\title{
THE TAXONOMIC VALUE OF THE CHARACTERS OF THE MALE GENITAL ARMATURE IN THE GENUS TETRANYCHUS DUFOUR.
}

\author{
By H. E. Ewing. \\ Oregon Agricultural College, Corvallis, Or.
}

\section{INTRODUCTION.}

The red spiders of the genus Tetranychus Dufour have always offered a knotty problem for systematists working in the order Acarina. When these mites were first noticed they were found on such a multitude of host plants, and showed such a great variation in color that the early workers considered the genus as being made up of a great many species or: varieties. Later it was found that certain well known forms could have a great variety of hosts, also that there was a considerable variation in size and color among individuals on a single host plant. Then there was a tendency to lump the forms together into a very few species, although confusion as to synonymy still. remained. In 1877 Professor A. T. Tozzetti called attention to the systematic value of the characters of the mouth-parts and of the tarsal appendages. Later Professor A. Berlese made use of some very important characters, the variations of the specialized setae on the palpal thumb. In $1900 \mathrm{Mr}$. N. Banks in his, "Red spiders of the United States," showed that the characters used by both of these authors were of special value in helping to separate our American forms. It is to Mr. Banks that we should give the credit for first straightening out many of the synonymous and wrongly determined species found in our country. But as yet, both in this country and in Europe, there is much confusion in regard to the identity and synonymy of some of our best known and most injurious species.

After examining hundreds of specimens from many parts of the United States, with magnifications up to 2000 diameters, and using an oil emersion lens, the present writer has found that the genital armature of the male is excellently adapted for systematic purposes.

The genital armature of the male may be considered as being composed of the penis, its attachments, and the slit-like opening through which it is protruded. For our purposes the penis alone 
will be considered, as it is well chitinized, quite visible, and offers great variations among different species, while only a few exist among individuals of a single species taken from the same host plant.

GENERAL STRUCTURE OF THE PENIS AND EXPLANATION OF

TERMS USED IN REFERENCE TO ITS PARTS. (See Figure.)

Inner lobe-The imbedded or attached part of the penis. It is much less chitinized than the penis proper.

Shaft-The free part of the penis. It is much more strongly chitinized than the inner lobe.

Basilar lobe-The enlarged proximal part of the shaft. It is not always present.

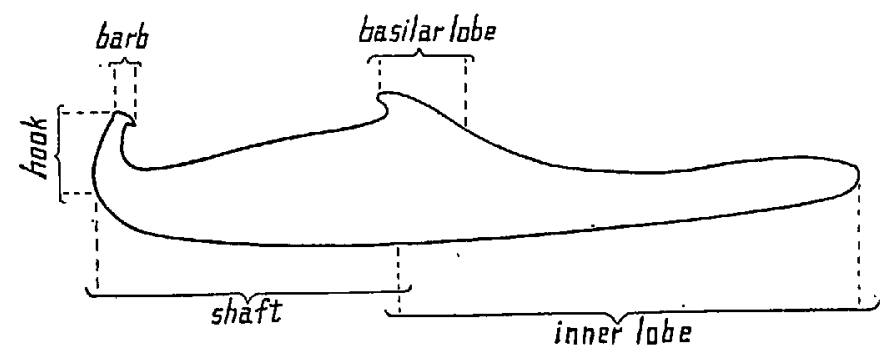

FIg. 1. Penis of male of Tetranychus telarius Linn., as seen from the right side, X 1800; showing the various parts delineated and labeled.

Hook-The dorsally curved distal part of the penis. It is. frequently absent.

Barb-The flattened or knobbed or bent tip of the penis.

Key to the Males thus far Examined.

I. 1. Penis long, tapering, without hook.

II. 1. Penis without basilar lobe; long, seta or spine-like.

III. 1. Shaft less than $0.04 \mathrm{~mm}$. in length, frequently doubly curved.............. T. weldoni $n$. sp.

III. 2. Shaft over $0.06 \mathrm{~mm}$. in length, with but a single curve................ Iongipes Banks.

II. 2. Penis with swollen part at the base of the shaft (basilar lobe).

III. 1. Shaft strongly curved; without barb..T. flavus n.sp.

III. 2. Shaft less curved; with flattened barb............

I. 2. Penis short, stouter, with hook.

T. borealis n. sp.

II. 1. Hook without barb.

III. 1. Hook bent at an angle of from $30^{\circ}$ to $50^{\circ}$ to the axis

of shaft............... m. mytilaspidis Riley

III. 2. Hook bent at an angle equal to at least $90^{\circ}$ to axis of shaft................ pratensis Banks

II. 2. Hook with prominent, flattened, recurved barb..............

T. telarlus Linn. 
NOTES ON OLD SPECIES AND DESCRIPTIONS OF NEW ONES.

In these notes three new species are for the first time here delineated. Before long the writer hopes to publish complete descriptions of these together with illustrations of those structures having special systematic importance.

Tetranychus telarius Linn.

Acarus telarius Linn.-Fn. Suec., 481, No. 1974 (1761).

This species appears to have the following American synonyms:

Tetranychus sexmaculatus Riley (?)-Insect Life, Vol. II., p. 225. (1890).

Tetranychus 2-maculatus Harvey-Ann. Rep't. Maine Agri. Exp. Sta,, part IV., p. 133, Pl. III. (1892).

Tetranychus gloveri Banks-The Red Spider of the United States. Tech. Ser. No. 8, Div. Entom., U. S. Dep't. Agri, p. 76. (1900).

This is our most common and most widely distributed species of red spider. It is also the most common species found in Europe. I give the following description of the penis of the male:

Penis short, stout. Inner lobe long, rod-like; longer than the shaft, and somewhat bent. Shaft thick, stout, short, much stouter at its base than at its distal end where it bears the prominent hook. Basilar lobe present, on the upper side of the shaft; it is small, protrudes slightly, and is hook-like in shape. Hook short, stout, extending dorsally; three or four times as broad at its base as it is at its apcx; it forms an angle of over $90^{\circ}$ with the apex of the shaft. Barb present at the end of the hook, flattened and recurved.

That our well known T. Q-maculatus Harvey is synonymous with $T$. telarius Linn. there can be but little doubt. I have sent specimens to Professor A. Berlese, of Italy, and after comparing them with the European species, he writes that they are the same. I have sent specimens to Dr. A. C. Oudermans, of Netherlands, and he states that they equal $T$. telarius L. I have received named female specimens of European individuals of $T$. telarius Linn. from Dr. Oudermans, which were collected from English elm (Ulmus campestris L.) at Amsterdam, October 1910. I have compared these females with the females of our $T$. bimaculatus Linn. I find in these specimens the presence of the same six bristles near the base of the tarsal pedicel of leg I. The four tenent hairs are similarly arranged and shaped in every respect as they are in our species. The tarsal pedicel is similar to our species. The tarsal claw is six cleft, and exactly like those I have examined in America. 
In the case of the palpal characters I find the same claw, thumb, finger, and sense hair; and each with the same form, relative size, and position as in our species. The thumb also bears the same three bristles; and one of the terminal spines is present. I find difficulty in getting a specimen in the right attitude to show both of the terminal spines properly.

The females show the structures of the genital and anal areas to be the same as in our species. The plate in front of the vulva is the same, and has the common two bristles. The anal papilla is the same as in our species, and is flanked on each side by two bristles as in our species. These bristles are of the same size, and are situated as in our species.

In this country Mr. Banks and others have recognized a form which has passed under the name of $T$. telarius Linn. I have compared our American forms of $T$. telarius Linn. with our ' $T$. bimaculatus Harvey, and I will state that after examining hundreds of specimens of both supposedly distinct species from many States (East, West and Middle) in this country, I can find no structural difference between the two. Mr. Banks, in his "Red Spiders of the United States," represents the thumb of the palpus of T. bimaculatus Harvey as bearing but one distal digit, a long seta, and a basilar spine; the thumb of $T$. telarius Linn. as bearing three distal digits, two small setae, and no basilar spine. By means of treatment with chloral hydrate solution or other clearing agencies, and by use of magnifications of over 2000 diameters, I find that there are more appendages to the thumb in both cases than Banks has represented. I find in both cases that the palpal thumb bears a large stout digit at its tip, above this two small, diverging spines or digits. Near the base in both cases is the spine which Banks has figured for $T$. bimaculatus Harvey. Toward the tip of the thumb and below the big finger is a large, curved seta also shown in Banks' figure of $T$. bimaculatus Harvey. Behind the basilar spine I find in all instances two more prominent bristles not figured in either Bank's drawing of $T$. bimaculatus Harvey or his drawing of $T$. telarius Linn.! Also I find that the tarsal claw in both cases is six-cleft instead of being four cleft as stated in Bank's paper!

There are some other points which I should like to mention in regard to the synonymy of these two species, but for the present I shall stop with these. 
Tetranychus sexmaculatus Riley may be the same as $T$. telarius Linn. I have. received many specimens of this species, sent by Professor H. J. Quayle, from Southern California. I find that the females agree with the females of $T$. telarius Linn. in every minute detail of structure. I have transferred live individuals to the common host plants of $T$. telarius Linn. Here they have not thrived successfully. In most cases they would not establish themselves. Unfortunately I have never examined a male of $T$. sexmaculatus Riley, and since so much depends upon the characters of the male genital armature we cannot be sure of the synonymy of the two species until a male specimen is examined.

Tetranychus gloveri Banks appears to be the same as $T$. telarius Linn. I have received scores of individuals of $T$. gloveri Banks, on cotton, from Georgia, sent by E. L. Worsham. These agree in all respects with my specimens of $T$. telarius Linn. collected from many places in the United States, and with the specimens of $T$. telarius Linn. received from Europe. Professor A. Berlese has examined specimens of $T$. gloveri Banks from cotton, and has considered it as being the same as $T$. telarius Linn.

\section{Tetranychus weldoni $\mathrm{n}$. sp.}

I have received many specimens of red spiders from G. P. Weldon labeled T. bimaculatus Harvey. For a long time I have considered that they were this species, which is, as I have shown, a synonym of $T$. telarius Linn. Recently I have found that the male is different from the male of the $T$. telarius Linn.

Female: Similar in all respects to the female of $T$. telarius Linn.

Male: Different from male of $T$. telarius $\mathrm{L}$. in characters of penis and spur on palpus. Spur on palpus not so pointed as in T. telarius Linn. Penis very long, rod-like; equal to a third the length of the body. Inner lobe short, rod-like, slightly swollen at its anterior end. Shaft, rod-like, not setiform; gradually tapering as you pass backward; posterior one half turned upward; tip narrowly rounded, not pointed. Basilar lobe absent. Hook absent. Barb absent.

From Grand Junction, Colorado; on apple, prune, and cotton wood; by G. P. Weldon.

\section{Tetranychus borealis $n$. $s p$.}

Female: Similar to the female of $T$. telarius Linn. but smaller, and never orange or red. The inner prongs of the tarsal claw are stouter than the inner prongs of the tarsal claw of $T$. selarius Linn. 
Male: Similar to the male of $T$. telarius Linn., except for the penis. Penis long, straight. Inner lobe about equal to basilar lobe in length. Shaft shaped like a slender rod. Basilar lobe very pronounced, coneshaped, equal to about one fourth the length of the shaft. Hook absent. Barb knob-like.

From Coast Range Moutains, Benton Co., Oregon; on Spirea sp.; by the writer.

This form is very closely related to another species, the discription of which follows.

Tetranychus flavus $n$. sp.

For over a year I have been studying a form of red spider which is a serious orchard pest in Oregon. It especially is injurious to apples when they are growing above an elevation of 1000 feet above sea level. In Hood River Valley I have found this form so serious as to discolor the leaves of whole orchards of apples, and in some instances as to cause defoliation late in the summer. When fall comes and the trees drop their leaves, these mites all become a pale yellow in color and collect in masses about the trunks of trees and the cracks of the ground for a region of several feet from the tree bases. Here they pass the winter, and become active again in the spring when the trees put out their foliage. At first I considered this species as but a form of our common $T$. telarius $L$. After studying these two forms for two seasons in the laboratory, I find that they must be considered as distinct species. This species is even more closely related to the one just described, $T$. borealis $\mathrm{n}$. sp. It may be described as follows:

General appearance similar to $T$. borealis n. sp.; also similar to $T$. telarius Linn., but the individuals are smaller. Color of immature forms green or yellow; of adults green or yellow, with black markings not pronounced. Adults are never orange or red. In the winter when deprived of food supply all instars yellow. General structures similar to those of $T$. telarius Linn., but the tarsal claw in most instances is only five-cleft, the two inner prongs being united. In $T$. telarius Linn., the tarsal claw is, I find, six-cleft; however, it has been represented by others as being four- cleft. In the case of the female of $T$. flavus the anal spines are situated farther forward than in T. telarius Linn., and also nearer the margins of the genital slit or opening. This species differs from $T$. borealis $\mathrm{n}$. $\mathrm{sp}$. in the tarsal characters which are nearer those of $T$. telarius Linn., and in having no barb to the penis.

The penis of this species is entirely different from the penis of $T$. telarius Linn. It is long and spine-like. In length it is equal to a third or fourth of the entire length of the body. Inner lobe of penis not prom- 
inent, slightly swollen at its anterior end; in size, smaller than the basilar lobe of shaft. Shaft long, curved, and resembling the sting of a wasp; varying greatly in curvature, generally bending downward, then upward, or it may have but a single curve, or it might be straight. Basilar lobe, large, subcylindrical, equal to over one fourth of the total length of the entire shaft. Hook and barb absent.

Generally distributed over Hood River Valley, Oregon; on apple trees especially; observed and reported by many people. Found in some places in the Willamette Valley, Oregon; on apples; by the writer. Probably present throughout the Pacific Northwest above altitudes of 1000 feet.

Tetranychus pratensis Banks.

Tetranychus pratensis Banks--Proc. Entom. Soc. Wash., Vol. XIV, p. 97. (1912).

I have examined specimens of this species, and find that the tarsal appendages are very peculiar. I find that there are two claws as stated by Banks, but only one, the outer, is simple. The inner claw is bent downward very near its base, and beyond. this bend it is three cleft. On each side of the tarsal claws is a short projection from which extends a pair of tenent hairs. The penis of the male may be described as follows:

Inner lobe slightly over one half as long as the shaft of the penis. Shaft stout, somcwhat similar to the shaft in $T$. telarius Linn.; enlarged slightly at its base so as to form the basilar lobe. Hook pronounced; bent at an angle of about $90^{\circ}$ to the axis of the shaft. Barb absent.

From Pullman, Washington; on timothy; by G. R. Hyslop.

Tetranychus mytilaspidis Riley.

Penthalodes mytilaspidis Riley-Hubbard, Orange Insects, p. 216. (1885).

This very characteristic red spider differs from most of our species in having the bristles of the body arising from prominent tubercles. In many respects it is about as far removed from $T$. telarius Linn. as any of the species of the genus. In the characteristics of the male genital armature it appears to be rather closely related to $T$. telarius Linn. The penis may be described as follows:

Inner lobe about one and a half times as long as the penis proper; not swollen at its anterior end. Shaft very short, and stout. A basilar lobe present in the form of a stout, more or less hook-like, protuberance on the dorsal side of the shaft. In this respect the penis is like that of T. telarius Linn. Hook very large, stout; bent at an angle of from $30^{\circ}$ to $50^{\circ}$ degrees to the axis of the shaft. Barb absent, but the distal part of the hook is bent out considerably. 
Generally distributed in Southern California on citrus trees, also found on deciduous trees. A serious pest of stone and pomaceous fruit trees in certain parts of Oregon.

Tetranychus longipes Banks.

Tetranychus longipes Banks-Proc. Entom. Soc. Wash., Vol. XIV., p. 27. (1912).

This species is so different from most of the other species in the genus, that it might well be made the type of a new genus. It has strong affinities with the genus Bryobia; in the general shape of the body, in the length of the anterior pair of legs, in the possession of the horn-like setae at the anterior end of the cephalothorax. I have examined the tarsal appendages of leg $I$, and find that with 2000 diameters magnification they are very complicated, and do not consist of two simple claws as Banks states. There is one large simple claw to the tarsus. Above this and apparently fused with it is a chitinous projection with many parallel hairs forming a comb. On either side of the tarsal claw is a pulvillus-like structure, each of which has several projecting tenent or other hairs.

I have observed but one male specimen of this species, and this specimen was very much dilapidated. What I have taken to be the penis may be described as follows:

Penis very large and long; much longer than the penis of any other species examined. Inner lobe about one third as long as the shaft, broadest at its base. Shaft long, curved, seta-like. Basilar lobe, hook, and barb absent.

From Springer, New Mexico; on grass (Agropyron); by C. N. Ainslie. From Holtville, California; by Wildermuth. 